\title{
Primary Traits Of Oral Business Presentation: Translatable Use For Assessment In A Virtual Learning Environment
}

Elke M. Leeds, (E-mail: eleeds@kennesaw.edu), Kennesaw State University Arjan Raven, (E-mail: araven1@kennesaw.edu), Kennesaw State University Dorothy Brawley, (E-mail: dbrawley@kennesaw.edu), Kennesaw State University

\begin{abstract}
As more and more classes are taught on-line, new challenges for assessment of student learning have come about. In this paper on the use of digital video $(D V)$ as an acceptable means to assess student oral business presentation skills, content analysis was used to test for the presence of primary traits inherent in effective formal business presentation. A specific set of traits was identified through a comprehensive literature review. Primary traits: eye contact or absence of reading, vocal variety, credibility or confidence, appearance of nervous mannerisms, and the purposeful use of the body represented the five independent variables in a one-level experiment. The five factors were accumulated into a survey instrument for use by study assessors experienced in evaluating formal business presentation skills. Study assessors looked at each speaker to determine if they could assess the five traits. Overall results indicated the five primary traits were noticeable $88.8 \%$ of the time, thereby rejecting the null hypothesis. This suggests that digital video may offer a technological solution for oral presentation skills assessment. This is an important finding for faculty in time and distance constrained environments. Future research is suggested to isolate quality characteristics in the digital film environment and to examine the impact that digital video has on student learning and skills.
\end{abstract}

\section{INTRODUCTION}

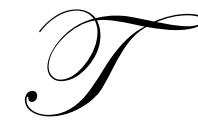

his paper evaluates the efficacy of digital video as a means to assess undergraduate business presentation skills in a virtual learning environment. It was initiated through secondary research by identifying valid attributes of effective formal business presentation. Primary research was conducted to determine if these attributes were measurable and translatable to the virtual learning environment (VLE) by indirect assessor observation and content analysis. A design of experiment analysis was conducted to test the validity of oral business presentation attributes through a study of $2^{\text {nd }}$ year undergraduate business information systems management students in a hybrid virtual learning environment. The test group received training in digital video technology and compression software to execute the on-line presentation requirements of the study.

\section{BACKGROUND AND PROBLEM}

The importance of communication skills in organizations has received much attention over the years (Butler, 1960; Downs \& Conrad, 1982; Drucker, 1954; Hildebrandt, Bond Miller, \& Swinyard, 1982; Hunter, 1983; McNaughton, 1963; Montzberg, as cited in Scudder \& Guinan, 1989). The oral exchange of information represents an increasingly important role in the function of today's companies (Warlum, 1988). From the university perspective, oral communication is recognized as one of the most important skills in helping graduating college students obtain employment. Accrediting bodies have also placed an increased emphasis on communication skills in 
the university setting (Ober, 1987). Many undergraduate business courses require students to perform oral presentations to prepare them for their future roles in the workplace (Campbell, Mothersbaugh, Brammer, \& Taylor, 2001). Presentation skill in particular is recognized as one of the seven most important oral communication skills needed by entry-level workers (Maes, Weldy, \& Icenogle, 1997).

In spite of this, an increase in classroom size and content obligations have forced many universities to adopt the large lecture class model (Geske, 1992), leaving little opportunity to devote time to in-class presentation. In a typical university setting, most courses provide feedback on relatively few oral presentations (Campbell et al., 2001). Time constraints and the pressures of larger class sizes deem this type of feedback, and the level of interaction it requires, impractical. As a result, the oral communication skills deemed essential by employers and accrediting bodies are often being overlooked in the classroom. (Wardrope \& Bayless, 1994). Continued employer emphasis combined with accreditation standards and large lecture class models are driving the meld of technology and innovation in oral communication and presentation instruction.

As business schools experience increased competitive pressures, Information Technology (IT) may be used to transform educational processes (Leidner \& Jarvenpaa, 1995). Presentation technology and, specifically, the use of digital video technology may act as a catalyst for transforming the way oral communication skills learning is assessed, if digital video passes a media richness test. Media richness theory suggests that some of the inherent characteristics of technology filter out cues that are necessary to provide information to the receiver. The richness of the media will directly impact the effectiveness of the technology in a particular situation (shepherd \& Martz, 2006). If digital video is to be considered for oral communication skills assessment in a virtual learning environment, the attributes of oral communication skill must pass through the technology lens so that the receiver is able to observe them. Media richness theory was used as the basis for this study's research questions:

RQ1: What oral communication attributes are associated with an effective formal business presentation?

RQ2: Are these attributes measurable and translatable to a digital video based virtual learning environment based on their ability to be recognized through digital video files?

\section{PRIMARY TRAITS IN ORAL BUSINESS COMMUNICATION}

As a first step to investigate digital video as a solution, a review of the literature on oral communication attributes was conducted. The review identified the most important attributes of oral communication, which are referred to here as primary traits. "Pedagogical practice related to oral business presentation has received little research attention despite the pervasiveness of oral presentations in business classrooms and their perceived importance to workplace success" (Campbell, et al., 2001, p.2). Through a review of the available literature, only a "handful of studies" (p. 2), journal published and peer reviewed, were available for analysis. This is contradictory to the trends that indicate that today's business schools exhibit strong interest in the field of oral communication (Sorenson, Savage, \& Oren, 1990). A focused investigation attempted to identify a set of specific delivery traits that were most often associated with successful oral presentation, in order to assess trait translatability to a virtual learning environment. The results are presented here:

\section{Eye Contact Or Absence Of Reading}

Eye contact or absence of reading was frequently represented in the literature. Effective communication is about getting messages across (Doumont, 2002). The physical behaviors associated with delivery are critical components of the communication process. Eye contact, or the absence of reading, has received a great deal of attention in communication literature as such a component. Eye contact is closely linked to credibility, interest in the audience, and nonverbal audience feedback (Kline, 2004). Genuine eye contact is more than a look in the direction of the audience. It is founded on an earnest desire to communicate. Effective eye contact is described as direct and impartial. A presenter looks directly into the eyes of the listeners, and impartially at all parts of the audience. Fitze \& McIntryre (2004) discussed eye contact as a means to demonstrate interest in the audience. Morgan (2001) related visual connection with an audience to kinesthetic speaking; dependent on visual stimulation and eye contact. 
Reliance on presenter notes interferes with connectivity and can make a presenter look unprepared or unapproachable (Fitze \& McIntyre, 2004). The inclusion of notes and/or electronic visual aids may inadvertently cause the speaker to read to the audience and thereby miss the opportunity to realize benefits associated with listener eye contact (Warlum, 1988).

H1 : $_{\text {: }}$ Eye contact or the absence of reading cannot be recognized in a digital video

H1: Eye contact or the absence of reading can be recognized in a digital video

\section{Vocal Variety}

Vocal Variety, like the other traits, has received much attention. Vocal variety incorporates clear diction, appropriate volume, and avoids unnatural verbal pauses and pronunciation problems (Kline, 2004). The speaker's voice is reasonably pleasant, understood, and can express noticeable differences in meaning. Communication theory states that listeners infer confidence, personality, credibility, and a speaker's likeability from vocal characteristics (Leathers, 1992). David Benady (2004) likened vocal variety to the successful totality of speech making. He restated Mucciolo's (1998) claim that only seven percent of presentation impact is due to the words used. Thirty-five percent is dependent on how things are said and how the information is presented. Much of the impact noted in a speakers' vocal variety stems from the advent of the television generation (Morgan, 2001). The intimate space created by television has created a need for conversational tones, relaxed vocal interaction, and a need for vocal intimacy. Most business presentations have not yet embodied this element. Verbal delivery is also most closely associated with presentation impact (Kline, 2004; Morgan; Tisdale, 2005). It is an important consideration when assessing the quality components in the delivery of a formal business presentation.

H2 : $_{\text {: }}$ Vocal variety cannot be recognized in a digital video

H2: Vocal variety can be recognized in a digital video

\section{Credibility And Confidence}

One of the most noted areas in effective communication indicates a need to adopt a "relaxed approach" (Wardrope and Bayless, 1994). This can also be one of the most challenging aspects of public speaking. The relaxed approach, sometimes witnessed through credibility or confidence is most closely associated with the fear of delivery. The fear of public speaking, which at times outranks the fear of death, has been a concern in the speech communication field for decades. Communication apprehension (CA) is defined as an individual's level of fear or anxiety associated with either real or anticipated communication with another person (McCroskey, 1977) While there are many solutions proffered in speech communication literature and practitioner's guides to combat anxiety and fear; a skills training focus is cited most often (Allen, Hunter, \& Donohue, 1989; Robinson, 1997). Skills' training typically includes elements related to teaching, practice, presentation, evaluation, and feedback (Tisdale, 2005). Tisdale and others (Bennett, 1999; Kline, 2004; Morgan, 2004; Robinson; Warlum, 1998; Woolf, 2001) recommend the use of video tape to analyze presentation anxiety levels. The results achieved when demonstrating credibility and confidence are notable. The audience achieves a comfort level with the speaker and the message is delivered more effectively (Kline).

$\mathbf{H 3}_{0}$ : Credibility or confidence cannot be recognized in a digital video

H3: Credibility of confidence can be recognized in a digital video

\section{Appearance Of Nervous Mannerisms}

Because the appearance of nervous mannerisms and the avoidance of anxiety received significant attention in the literature, a special examination of their impact on presentation success ensued. When a presenter displays non-purposeful body movements, nervous gestures, and/or distracting mannerisms, he or she creates a direct negative impact on presentation quality (Kline, 2004; Morgan, 2001; Tisdale, 2005). Business professionals are cognizant of such behaviors and strive to give better speeches and to control nervous behaviors (Campbell et al., 2001). Some presenters embody more anxiety than others. Students with communication apprehension (CA) are 
more easily predisposed to feelings of conspicuousness, being easily embarrassed, and being more likely to interpret audience reactions in a more negative manner that do less anxious speakers (Kolb, 1994). Second year undergraduate business students, being largely without prior presentation experience, may fall into this category.

H4 $_{0}$ : Absence of nervous mannerisms cannot be recognized in a digital video

H4: Absence of nervous mannerisms can be recognized in a digital video

\section{Gestures Or The Purposeful Use Of Body}

Body movements and purposeful gestures generally incorporate the use of hands, arms, shoulders and head to reinforce presentation purpose. Gestures are used to emphasize areas of importance or reinforce points made (Kline, 2004). These physical behaviors are important components of persuasive speech making (Curtis, Winsor, \& Stephens, 1995; Fitze \& McIntyre, 2004; Morgan, 2001; Tisdale, 2005; Woolf, 2001). Movement catches the eye of the listener, holds attention for good communication, and can reduce the physical distance between the presenter and audience (Kline, 2004). Movement has been noted as a potential distracter (Curtis et al; Kline; Fitze \& McIntyre; Morgan; Tisdale; Woolf) when associated with acts of nervousness or anxiety. Kline and Tisdale have recognized that oral presentation can occur with relatively little movement, but for formal business presentation, with a primary objective of persuasion, gestures and movements are necessary delivery traits. Doumont (2002) related all aspects of physical delivery with a summative statement: provide your audience that which they are most comfortable receiving.

H55: Gestures or the purposeful use of the body cannot be recognized in a digital video

H5: Gestures or the purposeful use of the body can be recognized in a digital video

\section{RESEARCH METHOD}

Five primary assessors and a control assessor were used as raters to validate the assessment. Each of the primary assessors were asked to watch 10 student-group created digital video files. The control assessor watched and rated all 50 student group created digital video files. Each of the assessors was asked to record the observability of each trait for each speaker. Each circled a one to indicate that the trait could be assessed in the video file or a zero to indicate that its presence could not be assessed. The use of the nominal scale in this research initiative allowed for a cleaner measure, prompting a common and structured response among the assessors. Benefits of qualitative design were realized as the data provided a deeper understanding on the phenomena in question within its natural context.

The qualitative approach simulated field research in situ by capturing the contextual nuances of student created presentations. Commonality in presentation length, content, recording equipment, editing software, and student instruction all contributed to the contextual environment. The methodology described also eliminated researcher bias by having assessors skilled in oral presentation assessment act as the observer in lieu of the primary researcher. The generation and use of documents and visual data do not inherently involve the researcher in social interaction as interviewing and observation do (Mason, 1996). The study methodology was unobtrusive as direct observation was filtered through the use of digital video files. Study respondents were never queried directly by assessors and risk of assessor respondent interaction was eliminated through the file and assessor anonymity (Leedy \& Ormrod, 2001; Marshall \& Rossman, 1989; Mason; Patton, 1980; Trochim, 2001; Yin, 1994). The method of content analysis was further enhanced by the study design which included web stored digital video files.

\section{Target Population}

The target population was comprised of a collection of undergraduate business presentations stored as digital video files. The files were created in the Business Information Systems Management (BISM) and Workplace Communication course and contained the representative data set of all measurements in which the investigator was interested (Aczel and Sounderpandian, 2002). 


\section{Sampling Procedure And Size}

The study included oral presentations conducted by business undergraduate students enrolled in the Business Information Systems Management and Workplace Communication course at a large southeastern AACSB accredited state university from January 1 of 2004 until May $31^{\text {st }} 2005$. The investigator retrieved files stored on fourteen different archived WebCT course sections. The digital video files were downloaded in batches by course number and semester.

A sample of 30 or more elements is generally large enough for the central limit theorem to take effect (Aczel \& Sounderpandian, 2002) and to ensure that a robust selection of speakers was made available for review. A subset from the population of $n=141$ digital video files was used to conduct the experiment. The videos contained between four and seven individual speakers each, resulting in a cumulative population of $n=567$ individual speakers available for analysis. Random number generation was used to isolate the data set of 50 digital video files for the sample. These 50 files contained $n=237$ individual speakers. A set of 10 files was identified for each primary assessor to view and assess according to the primary traits defined. Each primary assessor viewed between 46 and 50 individual speakers depending on the number of speakers in each file. The assessor viewing time ranged from 5 to 9 minutes per file and resulted in a cumulated viewing time commitment of 70 minutes on average per assessor. The control assessor evaluated all 50 files and 237 individual speakers following the same rating methodology as the primary assessors.

\section{Data Collection And Instrumentation}

Management and Business Information Systems Management (BISM) faculty members, including both full-time permanent and part-time temporary faculty, were assessors in this study. Assessors had previous experience in assessing formal business presentation skills in both face-to-face and virtual learning environments. Assessor identities were protected in all areas through a number identification process. A survey instrument, designed to record assessor responses according to the presence of a trait, was used as the primary data collection tool. It was structured as a dichotomous response questionnaire and contained a description of the 5 primary traits. Each assessor additionally provided unsolicited comments and feedback. As assessors watched each individual speaker, they recorded a corresponding 1 or 0 if the trait was recognizably present or not present. The sharing of additional comments and feedback was encouraged. Assessors were able to make notes on the instrument and share their thoughts on a particular trait or presenter.

\section{Validity Of The Instrument}

Validity was a primary concern in the design of the Primary Trait study. The researchers examined study and instrument validity at various points throughout the research initiative. The review of literature provided content validity as study traits were shown to be grounded in theory and scholarly works. Extreme care was given to an exhaustive review of each trait and its importance as defined by content experts. Internal validity, the extent to which research design and results allow the researchers to draw accurate conclusions, refers to the alignment of conclusions and research questions. In order for a study to possess internal validity, the conclusions must be warranted from the study as it was conducted (Leedy and Ormrod, 2001). The use of unobtrusive measures increased the probability that conclusions drawn were a direct result of the research design. This improved the likelihood that internal validity was present. External validity was also considered, but the exploratory nature of the study noted a trade-off between the ability to generalize about the data and a detailed view of the data in its contextual environment. The study did, however, present a representative sample and offers additional study opportunities in a comparison study incorporating face-to-face and virtual learning environments.

Instrument validity was also carefully examined. The validity of a measurement instrument is the extent to which the instrument measures what it is supposed to measure (Leedy \& Ormrod, 2001). Face validity and content validity were deemed equally important in the creation and execution of the survey instrument. Face validity of the instrument was assured through instrument design, ease of use, and the inclusion of the explanatory detail. Content validity centered not only on what traits were included, but also on how they were presented to assessors. 
Prior to officially distributing the survey instrument, several faculty members of the large southeastern state university that housed the study were asked to examine the instrument for content validity. The faculty members were contacted through personal communication and asked to ascertain instrument readability, comprehension level required for use, and an interpretation on the ease of use. The results of this informal pilot study, along with direction from the institutional review board and ethical standards in research committee, verified the clarity of the instrument and the appropriateness for data collection. Adjustments were made to improve the initial design of the instrument and to purport a high level of user-friendliness.

\section{Reliability Of The Instrument}

Reliability is the consistency with which a measuring instrument yields a certain result when the entity being measured hasn't changed (Leedy \& Ormrod, 2001). The researcher applied true score theory to the study instrument to ascertain the degree to which the assessor's observed score was indicative of the true score. True score theory maintains that every measurement is an additive composite of two components: true ability of the respondent on that measure and random error (Trochim, 2001). The true ability of the assessors was established through the careful selection of 6 unique assessors, well versed in assessing formal oral business presentations. Assessors possessed the ability to recognize the existence of the five traits inherent in effective oral business presentation in an ideal face-to-face presentation environment. The assessors were educated and/or have received professional grade training in business communication skills, oral presentation acumen, digital video presentations, the process to plan, tape, and upload digital media, and the classroom environment that housed the experiment.

Steps were taken to reduce measurement error through the informal pilot study previously described and through the use of the dichotomous scale to augment inter-observer reliability (Trochim, 2001). Additional consideration was given to whether respondents would answer truthfully. Given the assessors faculty identity, their direct experience with digital video, oral communication, and large enrollment class size, favorable respondent bias was considered. This was addressed through additional written and oral instruction.

Inter-rater reliability was also investigated. Each of the five primary assessors' scores was compared to a control assessor's score to determine the percentage agreement among assessors. Results of the score comparison are show in Table 1. Traits recognition agreement was present across all traits in over $82 \%$ of the cases between the control assessor and the 5 primary assessors. The highest agreement existed on the ability to recognize vocal variety and nervous mannerisms. Eye contact, credibility, and gestures were recognizable across assessors between 82 and $84 \%$.

Table 1 - Inter-rater comparison

\begin{tabular}{lccccc}
\hline Primary assessors & Eye contact & Vocal variety & $\begin{array}{c}\text { Credibility or } \\
\text { confidence }\end{array}$ & $\begin{array}{c}\text { Nervous } \\
\text { mannerisms }\end{array}$ & $\begin{array}{c}\text { Gestures or purposeful } \\
\text { use of the body }\end{array}$ \\
\hline $\begin{array}{l}\text { Number present } \\
\text { Percent present }\end{array}$ & 197 & 220 & 198 & 212 & 200 \\
\hline
\end{tabular}

\section{RESULTS AND ANALYSIS}

The five primary assessors recorded between 225 and 250 individual observations across the five traits under investigation. A total of 1,185 observations were made by the five primary assessors. In addition, the control assessor evaluated an additional 237 speakers on each of the five traits with observations totaling 1185.

In this section the cumulative results by assessor and trait are presented, along with an evaluation of the mean, variance and standard deviation of the findings by trait and discrepancies by assessor. 


\section{Results}

Results of the Primary Trait Analysis study are presented by trait specific results. Table 2 presents the primary trait presence by trait and by assessor. Table 3 presents the corresponding mean, variance, and standard deviation by trait. Across the assessors the ability to observe eye contact was $85.23 \%$. This rejects the null hypothesis that eye contact or the absence of reading cannot be recognized in DV. The results indicate that in most cases eye contact can be discerned from a digital video medium. Assessors one and three did not find that eye contact could be discerned to the same degree that the rest of the assessors did. A variance of 0.013 and a corresponding standard deviation of 0.113 were observed. There was still universal agreement that in more cases than not, eye contact or the absence of reading could be discerned from the digital video files.

Table 2 - Cumulative findings - Primary trait presence by trait by assessor

\begin{tabular}{|c|c|c|c|c|c|c|}
\hline Primary Assessors & One & Two & Three & Four & Five & Total \\
\hline Eye contact & 36 & 46 & 35 & 41 & 44 & 202 \\
\hline Traits present & $72.00 \%$ & $93.88 \%$ & $74.47 \%$ & $91.11 \%$ & $95.65 \%$ & $85.23 \%$ \\
\hline Vocal variety & 48 & 49 & 43 & 44 & 40 & 224 \\
\hline Traits present & $96.00 \%$ & $100.00 \%$ & $91.49 \%$ & $97.78 \%$ & $86.96 \%$ & $94.51 \%$ \\
\hline Credibility or confidence & 50 & 49 & 17 & 43 & 45 & 204 \\
\hline Traits present & $100.00 \%$ & $100.00 \%$ & $36.17 \%$ & $95.56 \%$ & $97.83 \%$ & $86.08 \%$ \\
\hline Nervous mannerisms & 50 & 48 & 27 & 38 & 45 & 208 \\
\hline Traits present & $100.00 \%$ & $97.96 \%$ & $57.45 \%$ & $84.44 \%$ & $97.83 \%$ & $87.76 \%$ \\
\hline $\begin{array}{l}\text { Gestures or purposeful } \\
\text { use of the body }\end{array}$ & 41 & 48 & 38 & 33 & 46 & 206 \\
\hline Traits present & $82.00 \%$ & $97.96 \%$ & $80.85 \%$ & $73.33 \%$ & $100.00 \%$ & $86.92 \%$ \\
\hline
\end{tabular}

Table 3 - Cumulative findings - descriptive results

\begin{tabular}{lccc}
\hline & Mean & Variance & Standard Deviation \\
\hline Eye contact & $85.39 \%$ & 0.013 & 0.113 \\
Vocal variety & $94.46 \%$ & 0.003 & 0.052 \\
Credibility or confidence & $85.94 \%$ & 0.078 & 0.279 \\
Nervous mannerisms & $87.57 \%$ & 0.032 \\
Gestures or purposeful use & & & 0.179 \\
of the body & $86.84 \%$ & 0.013 & 0.116 \\
\hline
\end{tabular}

The result for the primary trait of vocal variety more strongly rejects the null hypothesis. Study assessors were able to recognize vocal characteristics in digital video files with relative ease. The results indicate that in over $94 \%$ of occurrences, assessors were able to recognize a clear voice with appropriate volume, pauses and/or pronunciation characteristics. This is further supported by the variance and standard deviation. With a variance of 0.003 , assessors thought about the trait of vocal variety in largely the same manner. They were able to uniformly discern differences in vocal characteristics across multiple samples. This lends credence to the rejection of the null hypothesis that vocal variety cannot be recognized in digital video.

The third primary trait identified also supports rejecting the null hypothesis; that credibility or confidence can be recognized through digital video means. However, the results are not as convincing. The trait results surrounding credibility or confidence are affected by assessor number three's difference in assessment. The average prior to the inclusion of assessor three exceeds $98 \%$. With assessor three's scores, the average decreases to just over $86 \%$ agreements. The increase in variance occurred as result of assessor three's difference in assessment. The study 
assessor was only able to determine if a speaker appeared credible, had a comfortable presence, and was knowledgeable about subject matter in $36.17 \%$ of the occurrences. Yet the summative results are still acceptable for the rejection of the null hypothesis.

The fourth trait assessed, nervous mannerisms, displays results similar to the trait of confidence or credibility. Again study assessor three assessed the set of digital video files in a different manner than the balance of the study assessors. This assessor found that the trait of nervous mannerisms could not be discerned in digital video files $42.55 \%$ of the time. A review of assessor three's responses and analysis of possible reasons for the deviation will be addressed in the data analysis section. Again, the difference in assessment that assessor three reports is supported by the variance and standard deviation, though not to the degree that the trait of confidence and credibility is reported.

The final trait, gestures and purposeful use of body, findings are in alignment with the conclusions of the previous four. Again the null hypothesis that gestures or the purposeful use of the body cannot be recognized in a digital video is rejected. The overall report suggests that in almost $87 \%$ of the observations, the trait of gestures and movements was discernable through digital video files. While the overall percent of traits presents is congruent with the other traits reported, the variance of the fifth primary trait is more closely aligned with vocal variety and eye contact than it is with confidence and the appearance of nervous mannerisms. Study assessors did not vary greatly in their ability to discern whether or not the trait of gestures and body movements was present..

\section{Data Analysis}

Study findings indicate that the primary traits identified in the literature review may translate to the digital video medium well enough to support the effective evaluation of student oral business presentation delivery skills. The richness of the media was sufficient to allow the cues of an effective oral business presentation to reach the receiver. A cumulative examination of the primary traits shows that on average assessors could determine the existence of each of the primary traits at minimum, $85.23 \%$ in the samples viewed.

In the instance of vocal variety, assessors could determine the trait's existence in over $94 \%$ of samples viewed, demonstrating the upper end of the range. The high percentage result of a trait related to auditory perception led this researcher to consider the quality characteristics inherent in digital video technology. Digital video quality characteristics can be classified according to sound, light, and frame of the shot. The recognition of vocal characteristics was wholly dependent on the quality of the sound recording. Other primary traits depended largely on the effectiveness of the lighting used, or the position of the presenter in the camera frame. Each trait interacted with the quality characteristics differently. Sound is considered an important quality characteristic in the planning, capturing, editing, compressing, and viewing processes in digital video file preparation. Vocal variety was the only trait that relied solely on sound and was not dependent upon a visual examination of the presenter. For all but one assessor, this resulted in a higher that average report of the trait of vocal variety being present. This allows for the conclusion that the sound recorded was of a suitable high quality.

In an open ended comment provided by assessor five, the quality and dependence on sound is noted. Assessor five admitted a hearing deficiency and suggested that in subsequent studies, a microphone would benefit assessment in terms of sound quality and volume. It is important to note that assessor five scored vocal variety the lowest of any of the five traits; reporting that vocal variety could be discerned only $86.96 \%$ of the time. This corroborated the assessors' statement that having a personal hearing problem detracted from his ability to recognize the presence of vocal characteristics.

How the presenter is framed is another critical factor in the ability to analyze traits in digital video. If a presenter is recorded in a full body shot, nervous mannerisms, movement, pacing, and the purposeful use of the body can be easily recognized. If the presenter is recorded about the neck and shoulders, purposeful or non purposeful use of hands and arms can be disguised. The way the speaker is framed might affect an assessor's ability to detect body movements, nervous mannerisms, and even eye contact, if the speaker is set back in the camera frame. Lighting adds some of the same considerations to the set of primary traits. Too little light would challenge 
assessors ability to discern if eye contact was present. It might also affect how one perceives confidence or credibility if facial expressions are hidden in a dark shadow. Students with darker skin tones might require additional lighting to highlight the presenters' features. Another open ended comment provided by assessor five focused on the need to place African American students against a contrasting backdrop with a more direct versus indirect light source. This assessor found it more difficult to determine if eye contact was present when viewing digital video files with African American student presenters.

The researcher assumed that there would be samples of digital video files that would not adhere to the quality standards set forth by the researcher. The video files were created by 2 nd year undergraduate business information systems management students in a hybrid virtual learning environment. The test group was assumed to be without previous formal business presentation and without digital video preparation experience. The students received instruction in oral business communication and presentation skills as part of their course curriculum. The students also received training in digital video technology and compression software to execute the on-line presentation requirements of the study. Instruction was provided that identified the three characteristics of quality video footage. Students were instructed to test the level of direct and indirect light. They were also asked to shoot some test footage prior to taping to examine the frame of the shot, and to adjust the level of sound as needed. The degree to which the quality characteristics of the digital video files impacted the assessors' ability to determine if a trait was present is unknown. One can postulate about the affect light, sound, and frame might have, but would need to rely on further study to examine the impact accurately.

The combined total of the five primary traits across each of the five primary assessor and control assessor responses is shown in Table 4. Upon examination of the assessors' cumulative results it becomes apparent that assessor three recorded fewer traits present as compared to the other assessors. Assessor three posted an average percent of traits present of $68.09 \%$. These lower than average responses affected the total percent of traits present and thereby affected study outcomes. It was noted earlier that assessor three was only able to determine if a speaker appeared credible, had a comfortable presence, and was knowledgeable about subject matter in $36.17 \%$ of the occurrences. The ability to discern if nervous mannerisms were absent was also recognized to be below the mean of the other assessors at only $57.45 \%$. In a researcher led review of the files that assessor three scored; this researcher concluded that there weren't any notable quality differences in the files reviewed by assessor three as compared with those files reviewed by the other study assessors. A post study follow-up should be conducted to examine study methodology as a possible cause of variation. A subsequent change in methodology may also be warranted to address matters concerning video file quality more effectively. However with a combined total of $88.10 \%$, one can conclude that the primary traits were recognizable in a majority of cases across the majority of assessors. Additional inquiry is suggested to identify the source of the variance in assessor three's responses.

Table 4 - Cumulative findings - Primary trait presence by primary assessor

\begin{tabular}{|c|c|c|c|c|c|c|}
\hline Primary assessor & One & Two & Three & Four & Five & Total \\
\hline Number of speakers & 50 & 49 & 47 & 45 & 46 & 237 \\
\hline Total observations & 250 & 245 & 235 & 225 & 230 & 1185 \\
\hline Number of traits present & 225 & 240 & 160 & 199 & 220 & 1044 \\
\hline Percent of traits present & $90.00 \%$ & $97.96 \%$ & $68.09 \%$ & $88.44 \%$ & $95.65 \%$ & $88.10 \%$ \\
\hline
\end{tabular}

\section{DISCUSSIONS AND IMPLICATIONS}

This study offers an opportunity to examine the possibilities of digital video presentations in a hybrid virtual learning environment. Faculty assessors may benefit directly from this study through the availability of more class time as a result of digital video outsourced presentations. The incorporation of digital video technology in undergraduate education may create new opportunities for students constrained by distance and time to participate in a robust learning experience. The innovative use of technological applications in a virtual environment may improve student learning. This study may offer a different means to achieve potentially improved student learning outcomes. 


\section{Conclusions}

The Primary Trait study successfully identified 5 primary traits inherent in oral business presentation delivery. The specific set of traits was identified through a literature review and tested for their translatability to a virtual learning environment. It was shown through a case study of undergraduate business students enrolled in a business information systems and communications course at a large southeastern state university that the five traits could be used as a means to assess formal business presentation delivery skills. Research questions 1 and 2 were sufficiently answered and evidence exists to support these conclusions. In all cases, the null hypothesis was rejected.

The results of the study indicated that digital video may be a suitable alternative for in-class oral presentation. These results may have a far reaching impact on the ability to assess oral presentation skill through a virtual learning environment and to affect curricular design, delivery, and enrollment constraints. High enrollment classes will not be limited in their ability to include oral presentation as part of their curricular design. Class time previously monopolized by student presentations can be redirected. Students constrained by distance can receive feedback on oral presentation delivery in courses offered completely on-line. Courses limited in enrollment capacity due to in-class presentation requirements can be re-assessed for increased numbers. Institutions limited by physical building space can leverage digital video technology to expand their capacity constraints.

As the researchers progressed through the experiment and subsequent data analysis, several areas were noted where additional inquiry was suggested. These areas focused on a need to improve the assessment outcomes through better quality standards at project onset. The future use of digital video in a classroom setting was dependent on several quality characteristics not initially addressed by the Primary Trait study. Comments made by study assessors indicate that sound, light, and frame guidelines needed to be established for better assessment accuracy. Footcandle measures and portable sources of indirect lighting would have improved the assessor's ability to determine eye contact and confidence. Microphones were needed in one case to ensure quality output and reliable assessment in vocal variety, when the assessor was challenged with a hearing deficit.

Students received training on capturing footage and editing tape. Examples were provided that demonstrated the adequate and inadequate use of lighting, the importance of using a tripod for steady filming, and the problems associated with background noise interference. The quality characteristics highlighted in the student training may need to be better communicated prior to presentation taping. A possibility to improve video file quality would be to include a pre-test digital video presentation with student self evaluation prior to assessor evaluation. This would create an awareness of the digital video quality characteristics required for accurate assessment of the presentation delivery traits.

Study methodology was also reviewed. The inconsistency presented by assessor three brought the study instructions into question. Assessor three found that credibility or confidence could only be determined in $36.17 \%$ of the student presenters viewed. If assessor three's interpretation of credibility and confidence stood alone as an indicator of its ability to translate to the digital video environment, the null hypothesis would have been accepted, and the researchers would have concluded that credibility and confidence could not be discerned in a digital video medium. Assessors were asked to determine if the presenter appeared credible and knowledgeable about the subject matter. They were additionally asked if they were able to discern if the presenter had a comfortable presence and was confident with the subject matter. The inconsistency may have arisen from assessor three disregarding the second instruction. Assessor three may have responded that in $36.17 \%$ of the cases, presenters did not appear credible and knowledgeable about the subject matter, not that he or she was only able to determine if they appeared credible or confident in $36.17 \%$ of the cases. Though a face validity test of the instrument was conducted prior to release, a revised survey instrument with assessor follow-up is warranted to test against this inconsistency.

\section{Social Ramifications}

The social ramifications for the findings of research question 2 are important. Class time constraints directly affect the degree to which oral communication skills are taught in the classroom. Increased emphasis on the importance of oral communication and presentation skills suggest that an alternate means to address the time 
constraint may add benefit to students, faculty, and academies of higher education. The time needed to assess student public speaking skills can be made more efficient through the use of digital video technology when partnered with a course management system. This study has shown that the oral presentation delivery skills used in formal business presentations can be assessed in a virtual learning environment and that digital video taped files of oral business presentations may present an acceptable means of substitution for in-class oral presentation. As technology becomes more affordable, and hand-held devices with digital video capabilities become mainstream, leveraging these technologies to improve classroom effectiveness is a natural progression of events. If the use of digital video technology can be further tied to improved student learning, then additional positive social impact has been made.

\section{Recommendations}

There are several recommendations which can be made for practitioners using the Primary Trait Analysis Case Study for assessment purposes.

1. Modifications should be made to student digital video training that includes specific instruction on the digital video quality characteristics of sound, light, and frame.

2. Students should be given the opportunity to review their digital video presentations according to the trait assessment criteria, prior to submitting the file for assessment. This self-evaluative step may improve video file quality and assessment outcomes.

3. Microphones and portable light sources should be made available to students for use in capturing presentation footage.

4. An assessor training session is suggested to verify assessor instruction clarity. This would act as a substitute for the face validity method used in the Primary Trait Analysis Case Study.

It is additionally recommended that the instructions for the primary trait related to credibility or confidence be revised to read "Assessor is able to discern if the presenter has a comfortable presence and is confident with subject matter, or if the presenter is uncomfortable and is not confident with the subject matter." Implicit in each of these recommendations is the availability of digital video technology for campus use, the storage space availability for CMS viewing, and the password protected environment to ensure student protection and privacy.

\section{Further Research}

The Primary Trait Analysis Case Study has created several opportunities for additional research. One such opportunity is to determine if the study recommendations made will have a direct impact on study outcomes. As an extension, the study can be repeated with the same set of video files, but with an updated survey instrument and assessor training. As suggested previously, the survey instrument should be modified to provide clearer assessor instruction on credibility or confidence. Assessors should also participate in a pre-study training session with practice assessment files. While this would require a different assessor population, it would test the noted inconsistency of assessor three. The study can also be repeated with the same assessors, but with changes made to the student training and file submission process. More detailed exposure to the digital video quality characteristics prior to presentation taping is recommended. Student self review and access to additional equipment is also suggested. Together, these changes may improve assessment outcomes.

The five primary traits identified through the process of a literature review can be further validated. Secondary analysis was used to find commonalities in the literature. A more formal content analysis can be employed to exhaustively conclude that there are five, and only five primary traits associated with oral business presentation delivery. Following a thematic analysis of the literature, researchers could index the traits and quantitatively describe features of the text through frequency analysis. This would confirm the identity of the five primary traits inherent in oral business presentation delivery as necessary and sufficient. 
Finally, the Primary Trait Analysis Case Study can be used as a tool to measure changes in student learning outcomes as a result of digital video analysis. This higher level objective can be tested through a variety of face-toface versus virtual environments comparisons, using digital video analysis as the treatment.

\section{REFERENCES}

1. Aczel, A. D., \& Sounderpandian, J. (2002). Complete Business Statistics, $5^{\text {th }}$ ed. New York, NY: McGrawHill Higher Education

2. Allen, M., Hunter, J. E., \& Donohue, W. A. (1989). Meta-analysis of self-report data on the effectiveness of public speaking anxiety treatment techniques. Communication Education, Vol. 38, Issue 1, pp. 54-76.

3. Benady, D. (2004). Look who's talking. Marketing Week (UK) (Vol. 27, pp. 35-36): Centaur Communications.

4. Bennett, R. E. (1999). Using New Technology to Improve Assessment., Educational Measurement: Issues \& Practice (Vol. 18, pp. 5).

5. Campbell, K. S., Mothersbaugh, D. L., Brammer, C., \& Taylor, T. (2001). Peer versus Self Assessment of Oral Business Presentation Performance. Business Communication Quarterly, 64(3), $23-42$.

6. Curtis, D. B., Winsor, J. L., \& Stephens, R. D. (1995). National Preferences in Business and Communication Education, II. Paper presented at the Annual Meeting of the Central States Communication Association., April 1995.

7. Doumont, J.-L. (2002). The three laws of professional communication. Professional Communication, IEEE Transactions on, 45(4), 291-296.

8. Fitze, S., \& McIntyre, M. V. (2004). From Uncredible to Incredible: Tips for Speakers., Intercom (Vol. 51, pp. 8-10): Society for Technical Communication.

9. Geske, J. (1992). Overcoming the drawbacks of the large lecture class., College Teaching (Vol. 40, pp. 151): Heldref Publications.

10. Kline, J. A. (2004). Speaking Effectively - Achieving Excellence in Presentations. Upper Saddle River, N.J.: Pearson Education Inc.

11. Kolb, J. A. (1994). Adapting Corporate Presentation Skills Training Practices For Use in a University Classroom., Bulletin of the Association for Business Communication (Vol. 57, pp. 1): Association for Business Communication.

12. Leathers, D. G. (1992). Successful Nonverbal Communication, Principles and Applications. New York: Macmillan.

13. Leedy, P., \& Ormrod, J. (2001). Practical Research. Planning and Design. ( $7^{\text {th }}$ Ed.) New Jersey: MerrillPrentice Hall.

14. Leidner, D. E., \& Jarvenpaa, S. L. (1995). The use of information technology to enhance management school education: A theoretical view., MIS Quarterly (Vol. 19, pp. 265): MIS Quarterly \& The Society for Information Mgt.

15. Maes, J. D., Weldy, T. G., \& Icenogle, M. L. (1997). A managerial perspective: Oral communication competency is most important for business students... Journal of Business Communication (Vol. 34, pp. 67): Association for Business Communication

16. Marshall, C. \& Rossman, G. (1989). Designing Qualitative Research., Thousand Oaks, CA: Sage.

17. Mason, J. (1996). Qualitative Researching., Thousand Oaks, CA: Sage.

18. McCroskey, J. C. (1977b). Classroom Consequences Of Communication Apprehension. Communication Education,

19. Morgan, N. (2001). The Kinesthetic Speaker: Putting ACTION into WORDS., Harvard Business Review (Vol. 79, pp. 112): Harvard Business School Publication Corp.

20. Morgan, N. (2004). Preparing to Be Real. Harvard Management Communication Letter (Winter 2004): Harvard Business School Publication Corp.

21. Mucciolo, T. (1998). Your delivery will improve if you stay inside the triangle. Presentations, Vol. 12, Issue 3, p. 40.

22. Ober, S. (1987). The Status of Postsecondary Business Communication Instruction--1986 vs. 1982., Journal of Business Communication (Vol. 24, pp. 49): Association for Business Communication.

23. Patton, M. Q., (1980). Qualitative Evaluation Methods. Beverly Hills, CA. Sage. 
24. Robinson, T. E., II. (1997). Communication Apprehension and the Basic Public Speaking Course: A National Survey of In-class Treatment Techniques. Communication Education, 46(3), 188-197.

25. Scudder, J. N., \& Guinan, P. J. (1989). Communication Competencies as Discriminators of Superiors' Ratings of Employee Performance. Journal of Business Communication (Vol. 26, pp. 217): Association for Business Communication.

26. Sheppherd, M. \& Martz Jr., W. (2006) Media Richness Theory and the Distance Education Environment. Journal of Computer Information Systems, 47(1), 114-122

27. Sorenson, R. L., Savage, G.T., \& Orem, E. (1990). A Profile of Communication Faculty Needs in Business Schools and Colleges. Communication Education, 39(2), 148-160.

28. Tisdale, J. J. (2005). Effective Business Presentations. Upper Saddle River, N.J.: Pearson Education, Inc.

29. Trochim, W. M. K. (2001). The Research Methods Knowledge Base. Atomic Dog Publishing, Cincinnati, $\mathrm{OH}$.

30. Wardrope, W. J., \& Bayless, M. L. (1994). Oral Communication Skills Instruction in Business Schools. Journal of Education for Business, 69(3), 132-135.

31. Warlum, M. F. (1988). Improving oral marketing presentations in the technology-based company. Professional Communication, IEEE Transactions on, 31(2), 84-87.

32. Woolf, D. R. (2001). Stay Cool When Things Get Hot: How to Present and Communicate Your Ideas More Effectively., Business Credit (Vol. 103, pp. 18): National Association of Credit Management.

33. Yin, R. K., (1994). Case Study Research: Design and Methods $2^{\text {nd }}$ Ed. Thousand Oaks, CA: Sage. 


\section{NOTES}

